\title{
PELATIHAN MENGOPERASIKAN KIT PEMBELAJARAN BAGI GURU SD di KOTA PALANGKA RAYA
}

(The Training Of Operating Learning Kit For The Elementary Teachers In Palangka Raya)

Rita Rahmaniati, Bulkani dan Fazakkir Noor

\author{
Program Studi Pendidikan Guru Sekolah Dasar Fakultas Keguruan dan IImu Pendidikan \\ Universitas Muhammadiyah Palangkaraya \\ JI. RTA Milono Km.1,5 Palangka Raya, Kalimantan Tengah 73111
}

e-mail : rahmaniatirita@yahoo.co.id

\begin{abstract}
The aim of this dedication is to improve the teachers' professionalism in using elementary learning media/KIT in the city of Palangkaraya.

The method of this activity used in the form of training / worshop and the training results are presented by each teacher group, through stages 1) lecture 2) simulation 3) exploration 4) mentoring and 5) evaluation. The target audience or training participants were the classroom teachers and subject teachers at Muhammadiyah Elementary School in Palangkaraya city, as many as 19 people and also involves some of university students who have been trained using elementary learning KIT correctly.

The result of this dedication activity showed that: the ability of teachers in Elementary School of Muhammadiyah Pahandut Palangkaraya is $90 \%$ teachers has been skilled to both operate learning KIT and 10\% teachers in enough category and still need more guidance in operating KIT Learning.
\end{abstract}

Keywords: Learning KIT

\section{Abstrak}

Pengabdian ini bertujuan: untuk meningkatkan kemampuan profesionalisme guru dalam menggunakan media/KIT pembelajaran SD di kota Palangkaraya.

Metode kegiatan yang digunakan dalam pengabdian ini dalam bentuk pelatihan/worshop dan hasil pelatihan diperesentasikan masing masing kelompok guru, melalui tahapan 1) ceramah 2) simulasi 3) eksplorasi 4) pembimbingan dan 5) evaluasi. Khalayak sasaran atau peserta pelatihan adalah guru kelas dan guru mata pelajaran di SD Muhammadiyah pahandut kota Palangkaraya berjumlah 19 orang juga melibatkan beberapa mahasiswa yang telah dilatihkan menggunakan KIT Pembelajaran SD secara benar.

Hasil dari kegiatan pengabdian menunjukan bahwa: kemampuan guru di SD Muhammadiyah Pahandut kota Palangkaraya 90\% telah terampil dengan baik mengoperasikan KIT pembelajaran dan $10 \%$ pada kategori cukup dan masih perlu lebih banyak bimbingan dalam mengoperasikan KIT Pembelajaran.

Kata Kunci : KIT Pembelajaran 


\section{PENDAHULUAN}

Tuntutan abad 21 guru harus senantiasa berinovasi dalam pembelajaran dikelas . Inovasi yang dapat guru lakukan diantara nya inovasi dalam metode, strategi, pendekatan serta penggunaan media pembelajaran. Hal ini bertujuan agar guru dapat menyesuaikan dengan tuntutan yang ada agar pembelajaran dapat lebih optimal.

KIT Pembelajaran merupakan suatu kaedah inovatik sebagai alat/bahan bantu mengajar di sekolah. Bahan/ alat ini digunakan dan dilaksanakan oleh guru guru untuk menjadikan pengajaran dan pembelajaran menajdi lebih mudah dipahami oleh siswa. KIT pembelajaran untuk siswa SD ada berbagai jenis, diantaranya KIT pembelajaran IPA, KIT matematika, IPS dan bahasa Inggris.

Selama ini KIT pembelajaran untuk SD telah ada di masing masing sekolah, permasalahannya masih banyak guru yang belum terampil menggunakannya. Hal ini karena pengadaan KIT pembelajaran oleh dinas terkait belum disertai dengan pelatihan penggunaan / pengoperasian KIT pembelajaran tersebut atau hanya berdasarkan petunjuk yang tertera pada masing masing alat pembelajaran, sehingga KIT pembelajaran yang telah disediakan belum dapat di fungsikan secara optimal. Bahkan, peralatan KIT pembelajaran akan rusak sebelum dimanfaatkan.

Fakta lain menunjukkan bahwa selama ini guru belum pernah mendapatkan pelatihan penggunaan alat KIT pembelajaran baik yang diadakan oleh Dinas terkait maupun dari pihak manapun. Kegiatan pengabdian ini dapat membatu melatih guru guru untuk dapat mengenalkan KIT pembelajaran sekaligus menggunakannya sebagai media pembejaran pada materi materi tertentu yang relevan, sehingga siswa lebih termotivasi dalam pembelajarannya.

Melihat kondisi itu, dipandang perlu pelatihan pengoprasian KIT pembelajaran bagi guru SD. Pelatihan ini dimaksudkan agar KIT pembelajaran yang ada dapat di fungsikan sebagaimana seharusnya yaitu untuk membantu menunjang dan meningkatkan kualitas belajar mengajar di kelas. Selan itu, pelatihan ini juga mampu meningkatkan inovasi guru dalam menggunakan media pembelajaran sehingga mampu meningkatkan motivasi belajar siswa.

Hal ini merupakan perwujudan dari Permenagpan No 16 tahun 2009 yang tertuang dalam Pengembangan Keprofesian Berkelanjutan (PKB) bagi guru meliputi 3 hal, yaitu pengembangan, publikasi ilmiah dan karya inovatif. Karya Inovatif termasuk didalamnya : a) menemukan teknologi tepat guna b) menemukan/menciptakan karya seni c) membuat/memodifikasi alat pelajaran/ peraga/ praktikum, dan d) mengikuti pengembangan penyusunan standar, pedoman, soal dan sejenisnya.

Permenagpan No 16 tahun 2009 harus direspon oleh guru dengan mengikuti berbagai pelatihan yang terkait dengan pengembangan keprofesian berkelanjutan tersebut. Salah satunya pelatihan menggunakan/ mengoperasikan KIT / alat pembelajaran.

Adapun tujuan kegiatan pengabdian ini adalah untuk meningkatkan kemampuan profesionalisme guru dalam menggunakan 
media/KIT pembelajaran SD di kota Palangkaraya.

\section{METODE PELAKSANAAN}

Pelaksanaan Pengabdian masyarakat dilaksanakan selama 1 bulan sejak 9 maret 2016 sampai dengan 9 April 2016, bertempat di SD Muhammadiyah Pahandut Kota Palangkaraya. Khalayak sasaran atau peserta pelatihan adalah guru kelas dan guru mata pelajaran di SD Muhammadiyah Pahandut Palangkaraya berjumlah 19 orang juga melibatkan beberapa mahasiswa yang telah di latihkan dan mampu mengoperasikan KIT pembelajaran SD.

Kegiatan ini dilaksanakan dalam bentuk pelatihan (demonstrasi/ simulasi oleh para mahasiswa yang telah dilatih di ikuti oleh guru guru yang memegang alat yang sama hingga mampu mengoperasikannya) disertai tanya jawab pada saat kegiatan disertai proses pembimbingan pada saat guru guru melakukan unjuk kerja. Aktivitas selama 1 bulan kegiatan pengabdian dalam mengoperasikan KIT Pembelajaran dapat disajikan pada tabel .

Tabel 1. Pengoperasian KIT Pembelajaran 1 Bulan

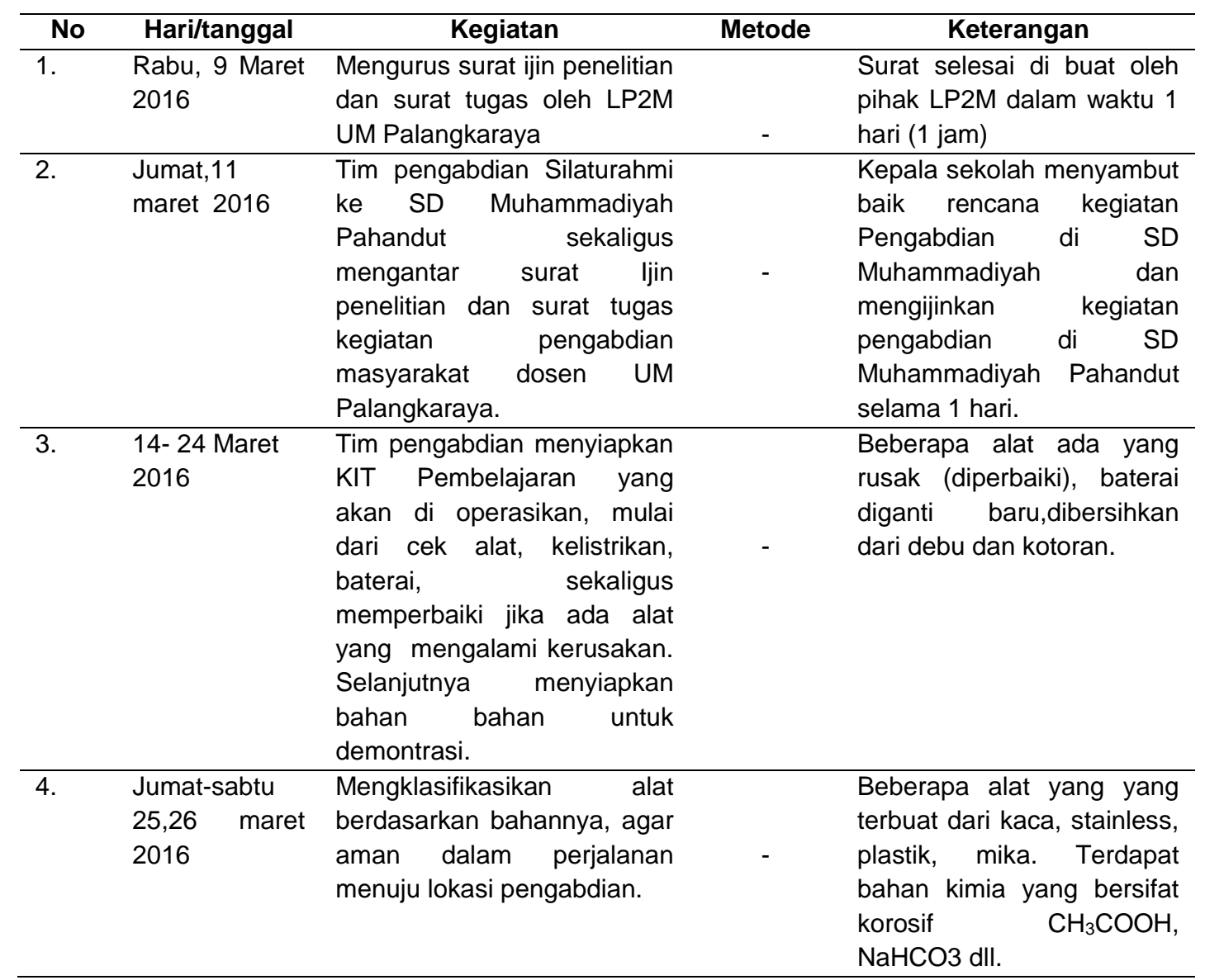




\begin{tabular}{|c|c|c|c|c|}
\hline No & Hari/tanggal & Kegiatan & Metode & Keterangan \\
\hline \multirow[t]{7}{*}{5.} & $\begin{array}{l}\text { Senin } 28 \\
\text { maret } 2016\end{array}$ & Tahap pelaksanaan & Ceramah & $\begin{array}{l}\text { Instruktur memperkenalkan } \\
\text { macam-macam alat KIT } \\
\text { Pembelajaran. }\end{array}$ \\
\hline & & & Simulasi & $\begin{array}{ll}\text { Selanjutnya } & \text { instruktur } \\
\text { dibantu } & \text { beberapa } \\
\text { mahasiswa yang } & \text { dilibatkan } \\
\text { mensimulasikan cara } \\
\text { mengoperasikan } \\
\text { KITpembelajarankegiatan } \\
\text { berlangsung } \pm 60 \text { menit }\end{array}$ \\
\hline & & & Eksplorasi & $\begin{array}{l}\text { insrukturt meminta peserta } \\
\text { dari masing-masing Guru } \\
\text { untuk mempraktekkan atau } \\
\text { mengoperasikan }\end{array}$ \\
\hline & & & & $\begin{array}{l}\text { Pembelajaran sesuai } \\
\text { sambil memperhatikan } \\
\text { simulasi yang di contohkan }\end{array}$ \\
\hline & & & $\begin{array}{l}\text { Tahap } \\
\text { pembimbi } \\
\text { ngan }\end{array}$ & $\begin{array}{l}\text { Selama guru guru } \\
\text { mensimulasikan } \\
\text { pembelajaran, instruktur } \\
\text { memberikan bimbingan. }\end{array}$ \\
\hline & & & Evaluasi & $\begin{array}{l}\text { Memberikan kesempatan } \\
\text { peserta pelatihan untuk } \\
\text { bertanya jawab terkait } \\
\text { dengan kegiatan yang telah } \\
\text { dilakukan. }\end{array}$ \\
\hline & & & Refleksi & $\begin{array}{l}\text { Tim pengabdian melakukan } \\
\text { refleksi hasil kegiatan } \\
\text { pelatihan. }\end{array}$ \\
\hline 6. & $\begin{array}{l}29,30,31 \\
\text { maret } 2016\end{array}$ & Tahap pelaporan & Menyusun & $\begin{array}{l}\text { Mengumpulkan semua } \\
\text { berkas dan dokumentasi } \\
\text { kegiatan pengabdian }\end{array}$ \\
\hline 7. & 1-9 april 2016 & & laporan & $\begin{array}{l}\text { Laporan terkumpul tepat } \\
\text { waktu. }\end{array}$ \\
\hline
\end{tabular}

\section{HASIL DAN PEMBAHASAN}

Hasil yang ingin dicapai dalam kegiatan pengabdian ini adalah $80 \%$ dari 19 orang guru terampil menggunakan KIT Pembelajaran secara benar. Yang dimaksud benar dalam hal ini sesuai dengan fungsi dan jenis masing masing KIT pembelajaran yang ada.
Pelatihan ini sangat bernilai/ bermanfaat bagi para guru di SD muhammadiyah yang telah mengikuti kegiatan pelatihan, karena selama ini guru guru peserta pelatihan belum terampil menggunakan media/ KIT pembelajaran. Padahal KIT pembelajaran tersedia lengkap di sekolah. Namun belum maksimal dalam pemanfaatannya. Ada beberapa alat yang sudah rusak yang disebabkan beberapa faktor, diantaranya 1) rusak 
(berkarat) karena tidak pernah digunakan dan teknik penyimapanan barang yang tidak tepat misalnya alat optik di simpan pada tempat yang lembab, 2) beberapa alat yang tidak lengkap bagian bagiannya, karena pernah digunakan tetapi tidak dikembalikan ke tempatnya semula, selain itu kerusakan alat disebabkan 3) kesalahan penggunaan, yang menyebabkan media/ KIT pembelajaran tidak dapat difungsikan karena patah, pecah dan alat optik yang dipenuhi jamur .

Hal ini dapat terjadi karena, KIT Pembelajaran yang di beli oleh sekolah atau dari bantuan Diknas tidak disertai dengan pelatihan penggunaan, hanya diberi buku petunjuk yang sukar dipahami oleh guru, sehingga pemanfaatan KIT Pembelajaran tidak maksimal. Padahal peran media / KIT pembelajaran sangat penting untuk digunakan sebagai media pembelajaran dikelas, karena siswa pada usia SD berada pada tahap berfikir praoperasional konkrit, sedangkan beberapa materi pelajaran di SD bersifat abstrak, sehingga penggunaan media dapat berperan sebagai perantara pesan dari guru ke siswa dari yang abtraks menjadi konkrit sehingga pembejalaran diharapkan dapat lebih efektif. Hal ini senada dengan pendapat Jennah (2009) Media pembelajaran adalah segala sesuatu yang dapat digunakan yang dapat menyalurkan pesan (bahan pembelajaran), sehingga dapat merangsang perhatian, minat, pikiran dan perasaan peserta didik dalam kegiatan pembelajaran tertentu untuk mencapai tujuan tertentu. Selain itu menurut Arsyad (1997) media memiliki empat tujuan antara lain :

a. Tujuan atensi, yaitu menarik dan mengarahkan perhatian peserta didik untuk berkonsentrasi kepada isi pelajaran yang berkaitan dengan makna yang ditampilkan.

b. Tujuan afektif, yaitu dapat terlihat tingkah kenikmatan peserta didik dalam belajar menggunakan media.

c. Tujuan kognitif, yaitu menambah wawasan dan pengalaman secara langsung dalamm proses pembelajaran.

d. Tujuan kompensatoris, yaitu media pelajaran terlihat dari hasil yang baik sebelum diberikan media.

Menurut Hamalik (2008) manfaat media adalah "manfaat dari media adalah sebagai bahan yang digunakan untuk membantu seorang guru menjelaskan materi pelajaran agar lebih mudah dipahami". Sedangkan menurut Kemp dan Dayton (Jennah, 2009) yang menyatakan manfaat media pembelajaran 1) Penyampaian pelajaran menjadi lebih laku, 2) Pembelajaran bisa lebih menarik, 3) Pembelajaran menjadi lebih interaktif, 4) Kualitas hasil belajar dapat ditingkatkan, 5) Sikap positif peserta didik dapat ditingkatkan, 6) Peran pembelajar dapat berubah kearah yang lebih positif.

Berdasarkan pendapat para ahli diatas dapat disimpulkan media belajar dapat membantu seorang guru menyampaikan materi pelajaran agar lebih mudah dipahami peserta didik. Guru Profesional sudah seharusnya mengoptimalkan proses pembelajaran di kelasnya, salah satunya terampil menggunakan KIT Pembelajaran.

Dari hasil kegiatan pelatihan mengoperasikan KIT pembelajaran menunjukkan bahwa 90\% guru dapat mengoperasikan KIT pembelajaran pada kategori baik dan $10 \%$ pada kategori cukup baik dan masih perlu bimbingan. Hal ini menunjukkan bahwa minat, respon dan keterampilan guru dalam mengoperasikan KIT 
pembelajaran dapat dikatakan sudah baik terlihat dari melalui kegiatan pelatihan.

Kemampuan guru SD Muhammadiyah dalam mengoperasikan KIT pembelajaran pada kategori baik diduga karena pada saat kegiatan pelatihan guru sangat antusias melakukan unjuk kerja yaitu mengoperasikan KIT pembelajaran dan tidak malu bertanya baik tentang penggunaan KIT baik pada saat simulasi berlangsung maupun setelah simulasi. Menurut Trianto (2012) kelebihan dengan menggunakan metode simulasi diantaranya adalah :

1. Simulasi dapat mengembangkan kreativitas, karena melalui simulasi orang dberi kesempatan untuk memainkan peranan sesuai dengan topic yang disimulasikan

2. Simulasi dapat memupuk keberanian $d n$ percaya diri

3. Memperkaya pengetahuan sikap dan keterampilan yang diperlukan dalam menghadapi berbagai situasi social yang problematis.

Dalam melakukan simulasi mengoperasikan KIT pembelajaran peneliti dan mahsiswa juga meminta peserta pelatihan untuk bertanya dan melakukan unjuk kerja dari simulasi yang telah dicontohkan. Menurut Mulyono (2012) metode tanya jawab juga memiliki kelebihan, yaitu 1) Suasana kelas lebih hidup karena berpikir aktif 2) Sangat positif untuk melatih untuk berani mengemukakan pendapat secara lisan dan teratur.

Menurut Setyono (2005) unjuk kerja merupakan keterampilan yang dirancang khusus untuk menghasilkan respon (lisan atau tulis), menghasilkan karya (produk), atau menunjukkan penerapan pengetahuan tugas yang diberikan.
Unjuk kerja yang dilakukan guru adalah menunjukkan penerapan pengetahuan tugas yang diberikan oleh peneliti dkk. Jika dalam mengoperasikan terdapat kesulitan, guru tidak segan bertanya atau meminta bantuan untuk diberikan bimbingan, seperti pada gambar 3 dan 4.

Gambar 1 dan 2 Simulasi pengoperasian KIT Pembelajaran
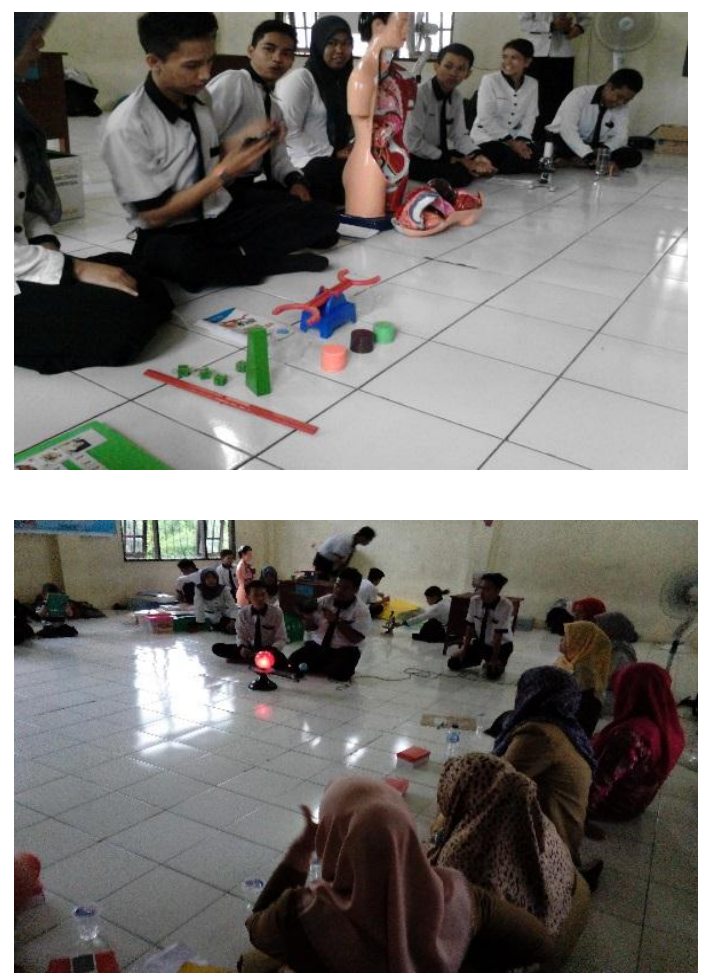

Gambar 3 guru mengoperasikan KIT pembelajaran dan meminta bimbingan

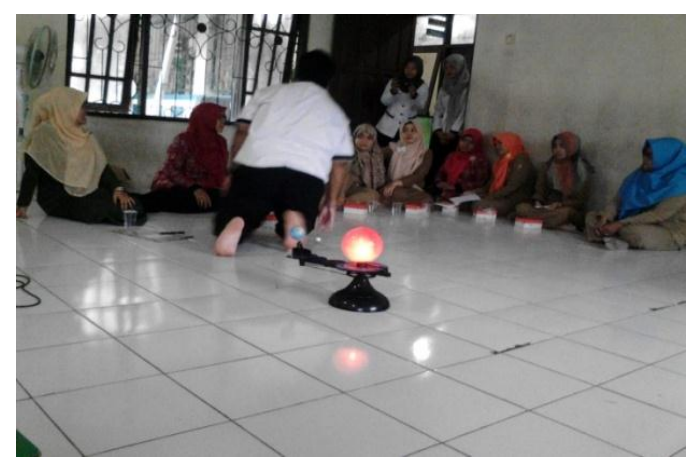


Gambar 4 menanggapi pertanyaan peserta pelatihan

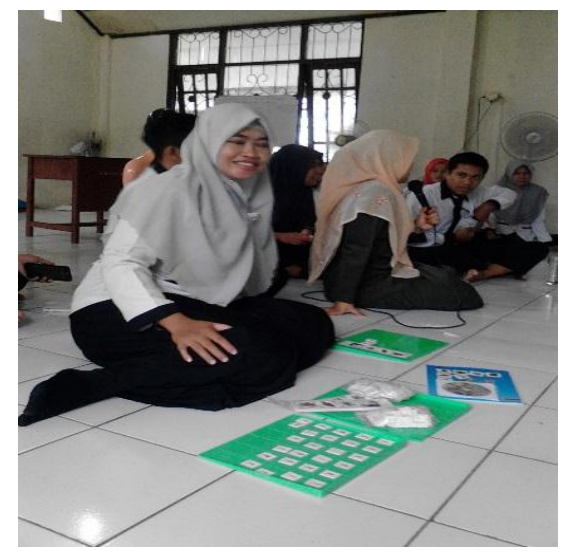

\section{SIMPULAN DAN SARAN}

\section{Simpulan}

Kegiatan pengabdian ini dalam bentuk pelatihan yang telah dilaksnakan, mampu meningkatkan kemampuan guru di SD Muhammadiyah Pahandut Palangkaraya dalam mengoperasikan KIT pembelajaran SD pada kategori baik $90 \%$ dan kategori cukup baik $10 \%$. Kegiatan pengabdian cukup sukses berjalan sesuai rencana, peserta cukup antusias mengikuti kegiatan pengabdian

\section{Saran}

1. Kegiatan pengabdian ini masih memungkin untuk dilanjutkan pada kegiatan peltihan mengoperasikan KIT pembelajaran pada alat yang lebih variatif sekaligus cara menyimpan alat dan cara merawat alat KIT pembelajaran dan peserta berasal dari beberapa Sekolah Dasar di kota Palangkaraya.

2. Perlunya penambahan dana kegiatan pengabdian msyarakat dari dana yang semula tersedia mengingat kegiatan pengabdian ini melibatkan beberapa sekolah.

\section{DAFTAR PUSTAKA}

Arsyad, Azhar. (2006). Media pembelajara. Yogyakarta: PT Raja Grafindo Pesada.

Jennah, Rodhatul. 2009. Media Pengajaran. Banjar Masin: Antasari Press.

Hamalik, Oemar. (2006). Proses BelajarMengajar Berdasarkan Pendekatan Sistem. Jakarta: Bumi Aksara.

Mulyono. 2012. Strategi Pembelajaran. Malang: UIN-Maliki Press.

Munadi, Yudhi. 2008. Media Pembelajaran. Jakarta: Gaung Persada Press.

Sadiman. Arif, dkk. (2007). Media Pendidikan. Jakarta: Rajawali prees.

Setyono, Budi.2005. Penilaian Otentik dalam Kurikulum Berbasis Kompetensi (dalam jurnal pengembangan pendidikan). Lembaga Pembinaan dan Pengembangan Pendidikan (LP3) Universitas Jember.

Susanto, A. (2013). Teori Belajar dan Pembelajaran. Jakata: PT. Kencana.

Syah, Muhibbin.2000. Psikologi Pendidikan. Bandung : PT. Remaja Rosdakarya

Wasliman. 2007. Teori Belajar Pembelajaran. Jakarta: PT Karisma Putra Utama.

Yamin \& Mukhtar. (2007). Kiat Sukses Mengajar di Kelas. Jakarta: PT. Nimas Multima. 